\title{
A Secreted Tumor-Suppressor, mac25, with Activin-Binding Activity
}

\author{
Mitsuo V. Kato \\ Department of Preventive Medicine, Kyoto Prefectural University of Medicine, \\ Kyoto, Japan
}

Accepted November 25, 1999.

\begin{abstract}
Background: mac25 is a follistatin (FS)-like protein that has a growth-suppressing effect on a p53deficient osteosarcoma cell line (Saos-2). The protein exhibits a strong homology to FS, an activin-binding protein, and part of its sequence includes the consensus sequence of the member of the Kazal serine protease inhibitor family.

Materials and Methods: Localization of mac25 protein was analyzed using mac25 protein fused with green fluorescent protein (GFP). Recombinant mac25 protein was expressed in E. coli and purified. The recombinant mac 25 protein was added in culture medium for analysis of growth suppression and cell cycle analysis. Binding of mac25 protein to activin A was studied by immunoprecipitation and Western blots analysis.
\end{abstract}

Results: mac25 protein was localized in the cytoplasm and secreted into culture medium. Addition of recombinant mac25 protein $\left(10^{-7} \mathrm{M}\right)$ into the culture medium induced significant suppression of the growth of human cervical carcinoma cells (HeLa) and murine embryonic carcinoma cells (P19), as well as osteosarcoma cells (Saos-2). mac25 protein was coimmunoprecipitated with activin A, a result that suggests that mac25 may be a secreted tumor-suppressor that binds activin A.

Conclusion: mac25 exhibits homology to insulinlike growth factor-binding proteins (IGF-BPs) and to fibroblast growth factor receptor. The multifunctional nature of mac 25 protein may be important for growth-suppression and/or cellular senescence.

\section{Introduction}

The mac25 gene was initially identified as a gene that is expressed at reduced level in meningiomas (1). The gene is expressed at high levels in senescent human mammary epithelial cells and its expression can be induced by retinoic acid (2). The human gene was mapped to chromosome $4 \mathrm{q} 12$ (2). Since human chromosome 4 can induce cellular senescence (3), mac25 may be associated with cellular senescence. The murine homologue was also cloned as a gene that had a growth-

Address correspondence and reprint requests to: Mitsuo V. Kato, Ph.D., Assistant Professor, Department of Preventive Medicine, Kyoto Prefectural University of Medicine, Kawaramachi-Hirokoji, Kamigyo-ku, Kyoto 602-8566, Japan. Phone: 181-75-251-5338; Fax: 181-75-241-0792; Email: mkato@basic.kpu-m.ac.jp suppressing effect on human p53-deficient osteosarcoma (Saos-2) cells (4). Murine mac25 consists of 281 amino acids (Fig. 1A). Although homology of mac25 (amino acids 30-60; Fig. 1B) to insulin-like growth factorbinding protein (IGF-BP) has been recognized, strong homology to follistatin (FS) has been also found (amino acids 100-150; Fig.1B), in particular in the case of the mouse homologue (4). Amino acids 117-126 (Pro-Val-Cys-GlySer-Asn-Gly-lle-Thr-Tyr; homologous to the consensus sequence of the Kazal serine protease inhibitor family) of mac25 are conserved in FS. The consensus sequence is also called the "follistatin module," because it is repeated three times in FS (5). The consensus sequence is also repeated nine times in agrin, a protein that is important for aggregation of acetylcholine and its receptor (6). This sequence has 


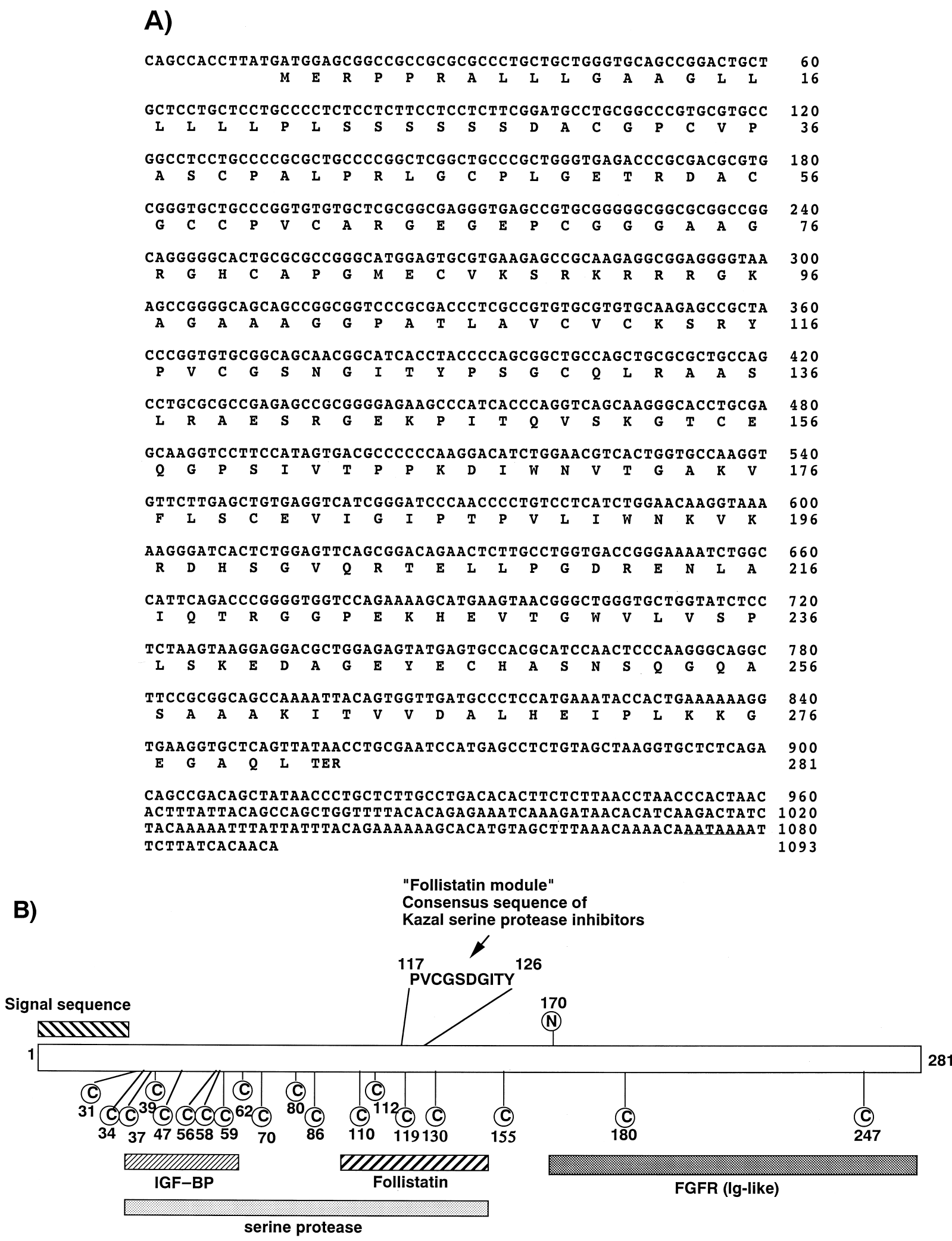

Fig. 1. (A) Nucleotide sequence and deduced amino acid sequence of the murine mac25 gene (GenBank accession No. L75822). A polyadenylation signal (AATAAA; nucleotides 1073-1078) is underlined. (B) The structure of murine mac25 protein. Highly conserved region (117-126) shows a significant homology to Kazal serine protease inhibitor consensus. Abbreviations: C, cysteine; FGFR, fibroblast growth factor receptor; IGF-BP, insulin-like growth factor-binding protein; N, A putative N-glycosylation site located at codon 170. 
not been found in IGF-BPs. Eighteen cysteine residues, putative sites of $S-S$ bonds, are also found in mac25 (Fig. 1B). The carboxyl terminus (about 30 amino acids) of FS is absent from mac25 (4). A carboxyl terminally truncated form (FS-288) of FS can be produced by alternative splicing (7) and it has stronger activin-binding activity than the longer form (FS-315) of FS (8). Therefore, mac25 is expected to have the same function as the truncated form of FS (FS-288). Homology to serine protease (amino acids 30-150) and to fibroblast growth factor receptor (FGFR) (amino acids 170-281) was also found (Fig. 1B).

mac25 can bind IGFs and the level of the expression of the gene is reduced in breast, prostate, colon, and lung cancers, in addition to meningiomas and osteosarcomas (9). These findings suggest that mac 25 may be a secreted protein with general tumor-suppressing activity. To elucidate the function of mac25, we analyzed the growth-suppressing effects of a mac25 recombinant protein on cell lines of osteosarcoma (Saos-2), cervical carcinoma (HeLa), and murine embryonic carcinoma (P19); as well as the localization of the protein using a recombinant protein consisting mac25 fused with green fluorescent protein (GFP), and the affinity of mac25 for activin A.

\section{Materials and Methods}

Cells

Osteosarcoma (Saos-2) cells and cervical carcinoma (HeLa) cells were cultured in Dulbecco's modified Eagle's medium (DMEM) supplemented with $10 \%$ fetal bovine serum (FBS). Embryonic carcinoma (P19) cells were cultured in DMEM supplemented with $7.5 \%$ calf serum and $2.5 \%$ FBS.

\section{Localization of mac25 Using GFP-fusion Protein}

cDNA of the murine mac25 gene was inserted, in frame, into the plasmid $p$ GFPNI upstream of the GFP gene (Clontech, Palo Alto, CA). The recombinant plasmid (designated $p C M V$-mac25GFP) was used to transfect Saos-2 cells by the diethylaminoethyl (DEAE)-dextran method (10). Cells were cultured for 2 to 3 days and observed under a fluorescence microscope (Leica, Leitz, Germany).
A Fusion Protein with Maltose-binding Protein (MBP)

cDNA of the murine mac25 gene was inserted, in-frame, into the plasmid pMal-cRI downstream of the $M B P$ gene (New England Biolabs, Beverly, MA). MBP-mac25 fusion protein was over-expressed in isopro-pylthio- $\beta$-D-galactoside (IPTG)-induced E. coli cells that harbored the fusion plasmid, and purified on a column of amylose resin (New England Biolabs). The resultant purified protein was added into the culture medium of tumor cells. Cells were counted after the addition of recombinant protein. For the cell cycle analysis, mac25-treated Saos-2 cells were fixed in ethanol, stained with forty $\mu \mathrm{g} / \mathrm{ml}$ propidium iodide (PI). The DNA content was monitored with FACscan (Beckton Dickinson, San Jose, CA).

\section{Binding of mac25 Protein to Activin A}

Cell lysates were extracted from Saos-2 cells transfected with $p C M V$-GFP (control vector, same as $p G F P N 1)$ or $p C M V-m a c 25-G F P$ in TNE buffer $(10 \mathrm{mM}$ tris pH $7.8,1 \% \mathrm{NP} 40,1.5 \mathrm{M}$ $\mathrm{NaCl}, 1 \mathrm{mM}$ EDTA, $10 \mu \mathrm{g} / \mathrm{ml}$ aprotinin). Supernatants of cultured Saos- 2 cells transfected with plasmids were also used for the analysis. Aliquots of cell lysates and culture medium (1 mg of protein per aliquot) were mixed with 2 $\mu \mathrm{g}$ of recombinant human activin A, provided by the National Hormone and Pituitary Program (NHPP), Lot\# 15365-36 (Rockville, MD) (1). The proteins were immunoprecipitated with antibodies against GFP (Clontech) or against human activin A (Austral Biologicals, San Ramon, CA) and protein G (Pharmacia, Uppsala, Sweden). Co-precipitated complexes were confirmed by reciprocal immunoblotting analysis with the same antibodies as mentioned above.

\section{Results}

\section{Localization of mac25-GFP Fusion Protein}

Figure 2 shows Saos-2 cells transfected with $p C M V$-GFP (control vector; Fig. 2A) and with $p C M V$-mac25-GFP (Fig. 2B). Fluorescence was emitted from the entire cytoplasm and nuclei. However, fluorescence was emitted from specific regions of the cytoplasm of cells expressing the mac25-GFP fusion protein and not from their nuclei. Because mac25 has a signal se- 


\section{A) pCMV-GFP (Saos-2 cells)}

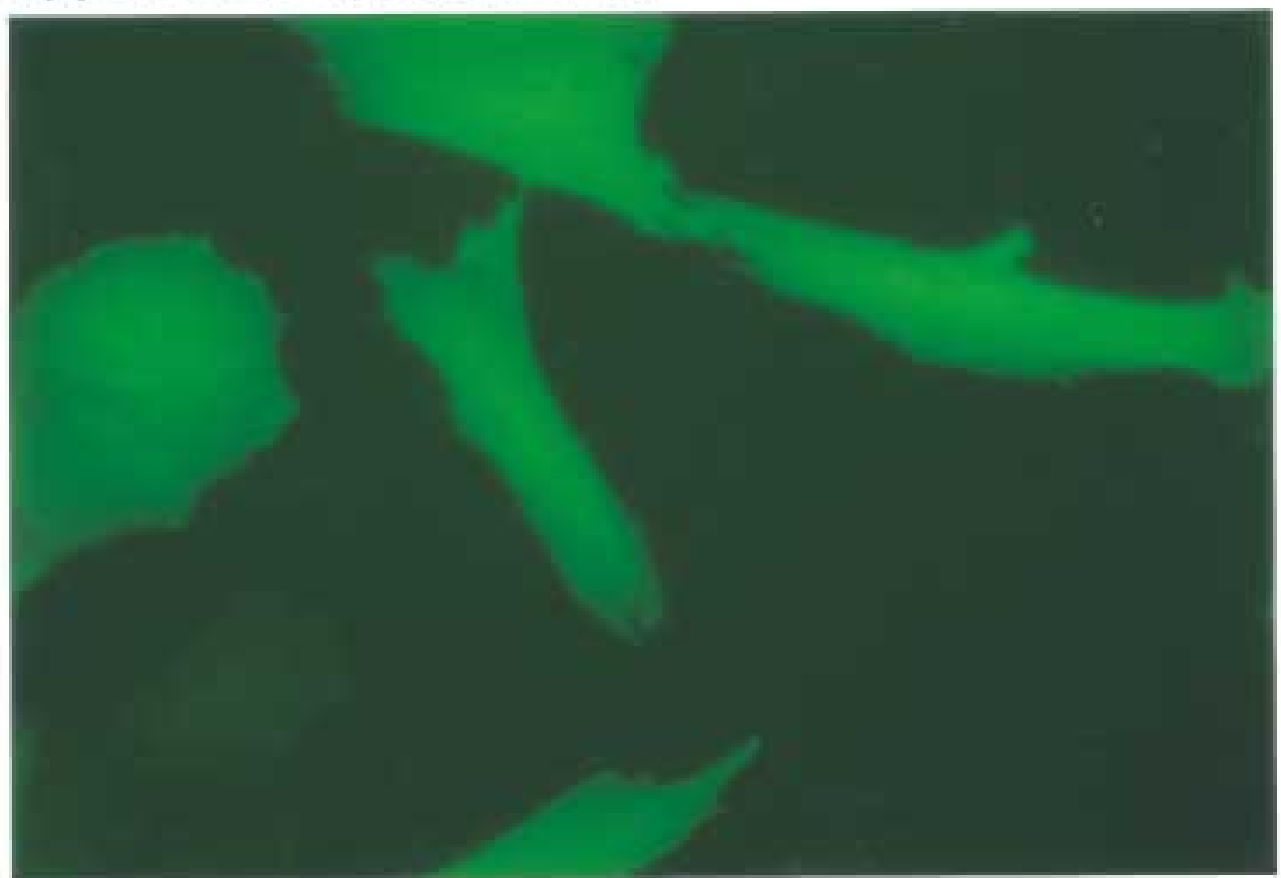

B) pCMV-mac25-GFP (Saos-2 cells)

Fig. 2. Localization of mac25 protein. (A) Saos-2 cells transfected with the control vector. Fluorescence was emitted from entire cells. (B) Saos-2 cells transfected with the mac25-GFP fusion construct. Fluorescence was emitted only from cytoplasmic regions. Cells were photographed at $200 \times$ magnification. 
quence at its amino terminus, cell lysates and conditioned medium of the cells expressing the mac25-GFP fusion protein was examined (Fig. 3). The mac25-GFP fusion protein was detected both in the cell lysate and medium. Since there was no significant difference between the molecular masses of the protein detected in the lysate and the medium, the extent of modification of the protein appeared to be limited and mac25 protein was confirmed to be a secreted protein. Although plasmid pCMV-GFP-mac25 (mac25 inserted in downstream of GFP) was also constructed and transfected to Saos- 2 cells, no GFP-positive cells were detected (data not shown).

Growth-suppressing Activity of Recombinant mac25 Protein

Since no evidence for significant modification of the mac25 protein was obtained (Fig. 3), a recombinant protein in which mac25 was fused with maltose-binding protein (MBP) was expressed in E. coli and purified. When the recombinant mac25 protein was added into the culture medium, growth of the Saos-
2, HeLa and mouse P19 cells was significantly reduced at a concentration of $10^{-7} \mathrm{M}$ (Fig. 4). Morphological changes due to mac25 are shown in Fig. 5. Although the number of viable Saos-2 and HeLa cells was very much reduced after treatment of with mac25 for 3 days, some viable cells were observed (Fig. 4 and Fig. 5B, 5D). By contrast, no viable cells were observed in P19 cells treated with $10^{-7} \mathrm{M}$ mac25 protein for 3 days (Fig. 4 and Fig. 5F).

The fraction of G1 phase of Saos-2 cells after treatment $(72.6 \%)$ with $10^{-7} \mathrm{M}$ mac25 protein for $12 \mathrm{hr}$ was considerably larger than that of the untreated cells $(56.8 \%$ ) (Fig. 6). The fraction of G2/M phase of treated cells (14.8\%) was about half of that of untreated cells $(28.3 \%)$.

\section{Binding of mac25 Protein to Activin A}

Since mac25 protein exhibits significant homology to FS, an activin-binding protein (4), binding of mac25 to activin A was analyzed. The lysate and the culture medium of Saos-2 cells expressing mac25-GFP protein were

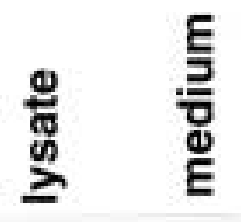

$69 \mathrm{kDa}-$

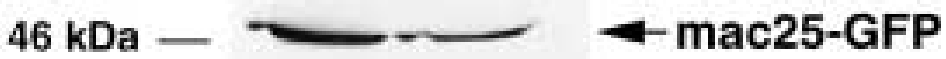

$30 \mathrm{kDa}$

\section{$21.5 \mathrm{kDa}$}

$14.3 \mathrm{kDa}$
Fig. 3. Western blots analysis of the mac25-GFP fusion protein. The cell lysate and the culture medium of Saos- 2 cells transfected with the mac25-GFP fusion construct were analyzed. No difference was detected between molecular masses of the protein in the lysate and the medium. 
A)

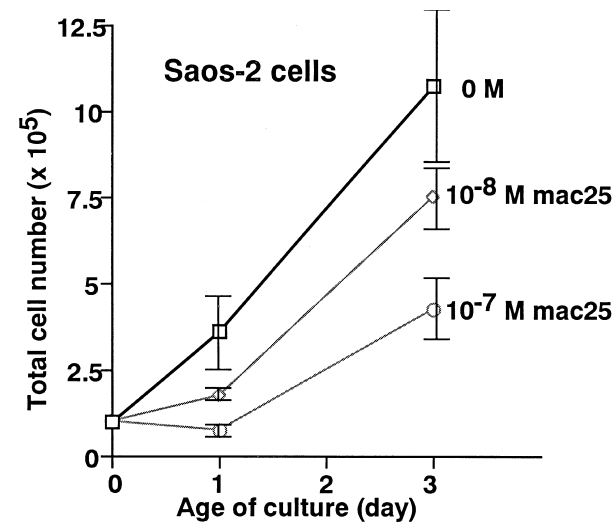

B)

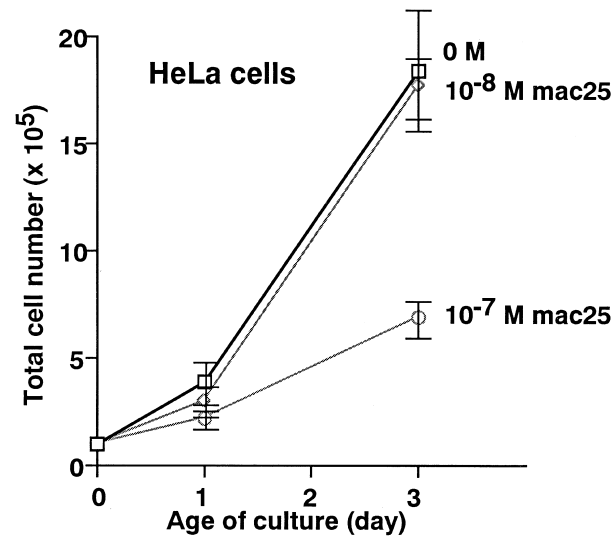

C)

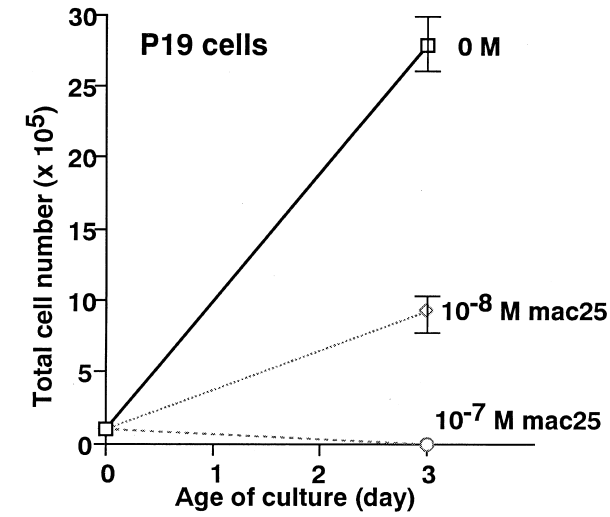

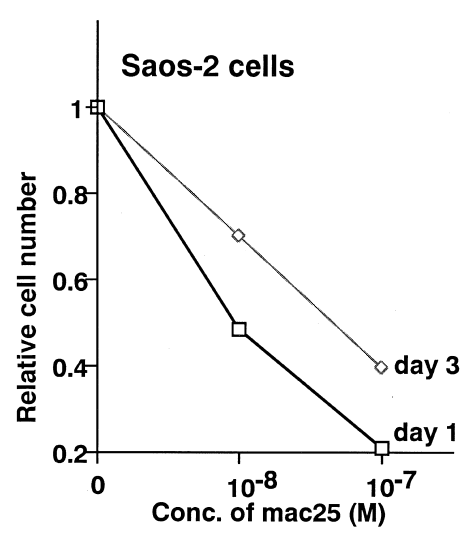
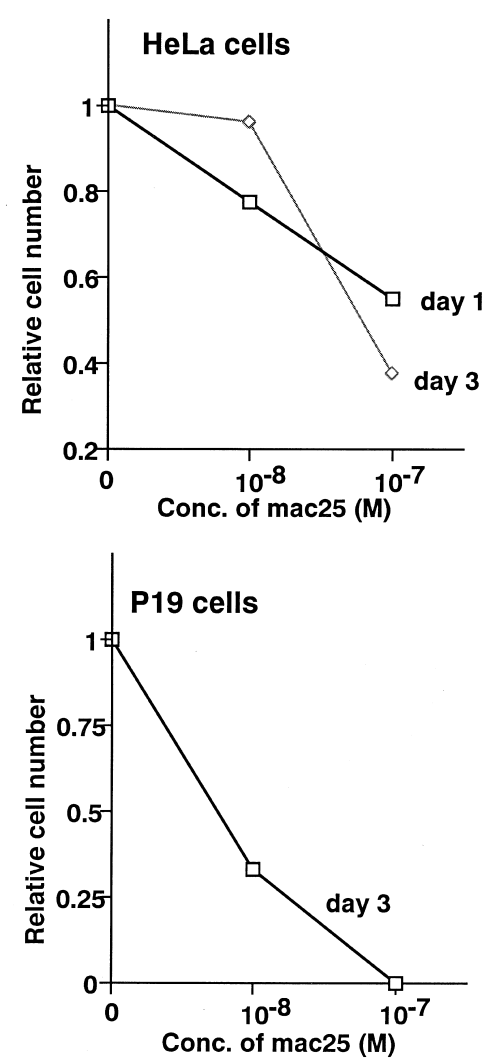

Fig. 4. Effects of mac25 recombinant protein on the growth of cultured tumor cells. $10^{5}$ cells of each cell line were inoculated and the numbers of cells were counted after 1 and 3 days. Left panels show the total cell numbers against culture day. Bars indicate standard deviations. Right pan- els show changes in fractions of viable cells plotted against the concentration of mac 25 recombinant protein. Upper, middle and lower panels show the results for Saos-2 cells, HeLa cells and P19 cells, respectively. mixed with human recombinant activin $\mathrm{A}$ and immunoprecipitated with antibodies against activin or GFP. Precipitates were analyzed by Western blot analysis. Activin A was detected as one of the proteins that were immunoprecipitated with antibody against GFP when Saos-2 cells expressed the mac25-GFP protein, but was not detected in lysates precipitated with antibody against GFP when cells expressed GFP only (Fig. 7A). Reciprocal analysis yielded similar results (Fig. 7B). Because GFP did not associate with activin A, it seems likely that mac25 can specifically bind to activin A. 

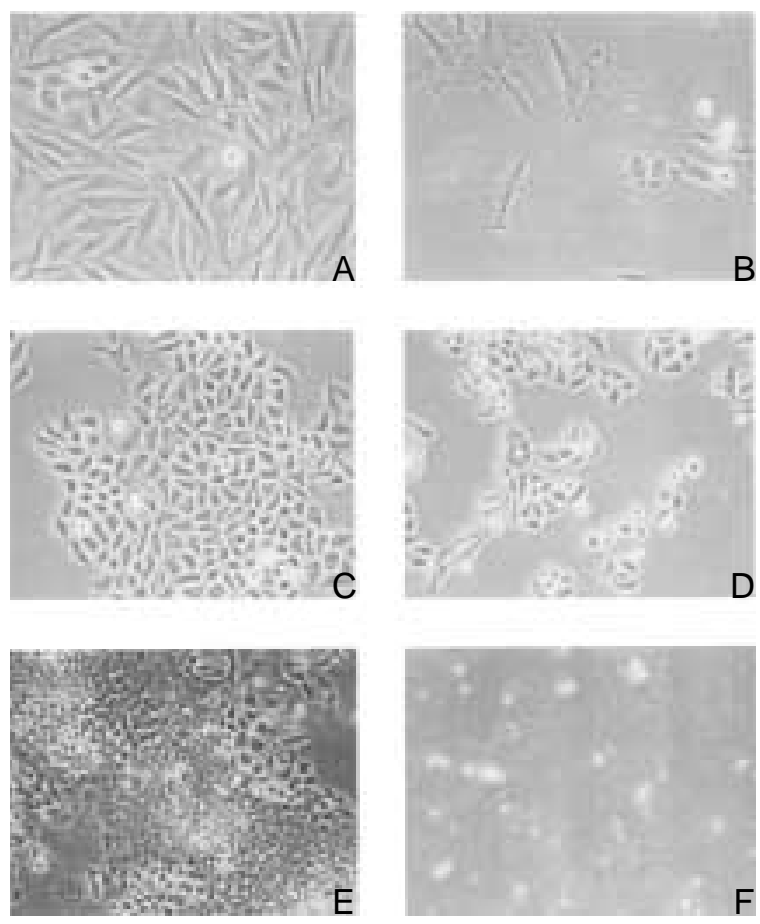

Fig. 5. Morphology of mac25-treated cells $\left(10^{-7}\right.$ M mac25). (A) Saos-2 cells cultured for 3 days. (B) mac25-treated Saos-2 cells. (C) HeLa cells. (D) mac25-treated HeLa cells. (E) P19 cells. (F) No viable P19 cells were observed after treatment with mac25 for 3 days. Cells were photographed at 100 $\times$ magnification.

\section{Discussion}

The mac25 protein exhibits strong homology to FS, in particular, with respect to the consensus sequence of the Kazal serine protease inhibitor family. The consensus sequence is repeated three times in FS and is also called the "follistatin module" (5). The sequence is also repeated in agrin, a protein important for the aggregation of acetylcholine and its receptor (6). Therefore, the consensus sequence may be important for binding to some other protein and/or for aggregation of several associated proteins, rather than for action as a protease inhibitor. mac25 has also been identified as an adhesion factor (11). The conserved region may be important for proteinprotein interaction and mac25 may associate with activin to suppress the growth of tumor cells.

mac25 was localized exclusively in cytoplasmic regions. It was secreted into the cul- ture medium and suppressed the growth of various tumor cells lines, in addition to an osteosarcoma cell line. Thus, mac25 may be a general growth-suppressor. The viability of Saos- 2 cells and HeLa cells was extremely reduced after addition of mac25 protein into the medium, but some viable cells remained. However, no viable P19 cells were observed after treatment with mac25 recombinant protein at $10^{-7} \mathrm{M}$ for $72 \mathrm{hr}$ (Fig. 3 and Fig. 4). mac25 may induce cell death rather than growth-suppression of P19 cells. Expression of mac25 can be induced by retinoic acid (2). Retinoic acid and bone morphogenetic proteins (BMPs), other members of the transforming growth factor (TGF) $\beta$ superfamily, induce apoptosis in P19 cells $(12,13)$. Apoptosis in P19 cells might be induced by up-regulation of mac25 in response to retinoic acid.

mac2 25 protein binds activin A and similar binding is an important function of FS (14). mac25 may also regulate the signaling of the TGF- $\beta$ superfamily, causing growth suppression and/or cell death. Initially, we cloned the mac 25 gene as a gene with an anti-proliferative effect on p53-deficient osteosarcoma cell line (Saos-2), similar to that of p53 (4). p53 is a transcriptional factor that up-regulates the expression of a cyclin-dependent kinase-inhibitor (CDKI), p2 1 (15). TGF- $\beta$ signaling is also associated with activation of other CDKIs, p15 (16) and p27 (17). mac25 and p53 may have a similar target (CDKI). Saos- 2 cells treated with mac 25 were arrested at the Gl phase of cell cycle. Modulation of TGF- $\beta$ signaling by mac 25 may be one of the keys to the regulation of the cell cycle.

mac 25 is strongly expressed in senescent cells and the human gene was mapped to the chromosome 4q12 (2). Human chromosome 4 induces cellular senescence of cervical carcinoma (HeLa), bladder carcinoma (J82) and glioblastoma (T98G) cell lines (3). Loss of heterozygosity $(\mathrm{LOH})$ on chromosome $4 \mathrm{q}$ has been detected in hepatocellular carcinoma (18-20), bladder carcinoma (21), cervical carcinoma $(22,23)$, lung cancer $(24,25)$, esophageal adenocarcinoma (26), papillary thyroid cancer (27), head and neck squamous cell carcinoma (28), and childhood acute lymphoblastic leukemia (29). Loss of antiproliferative or apoptotic activity accompanied by chromosomal deletion of the mac 25 gene 


\section{Saos- 2 cells}
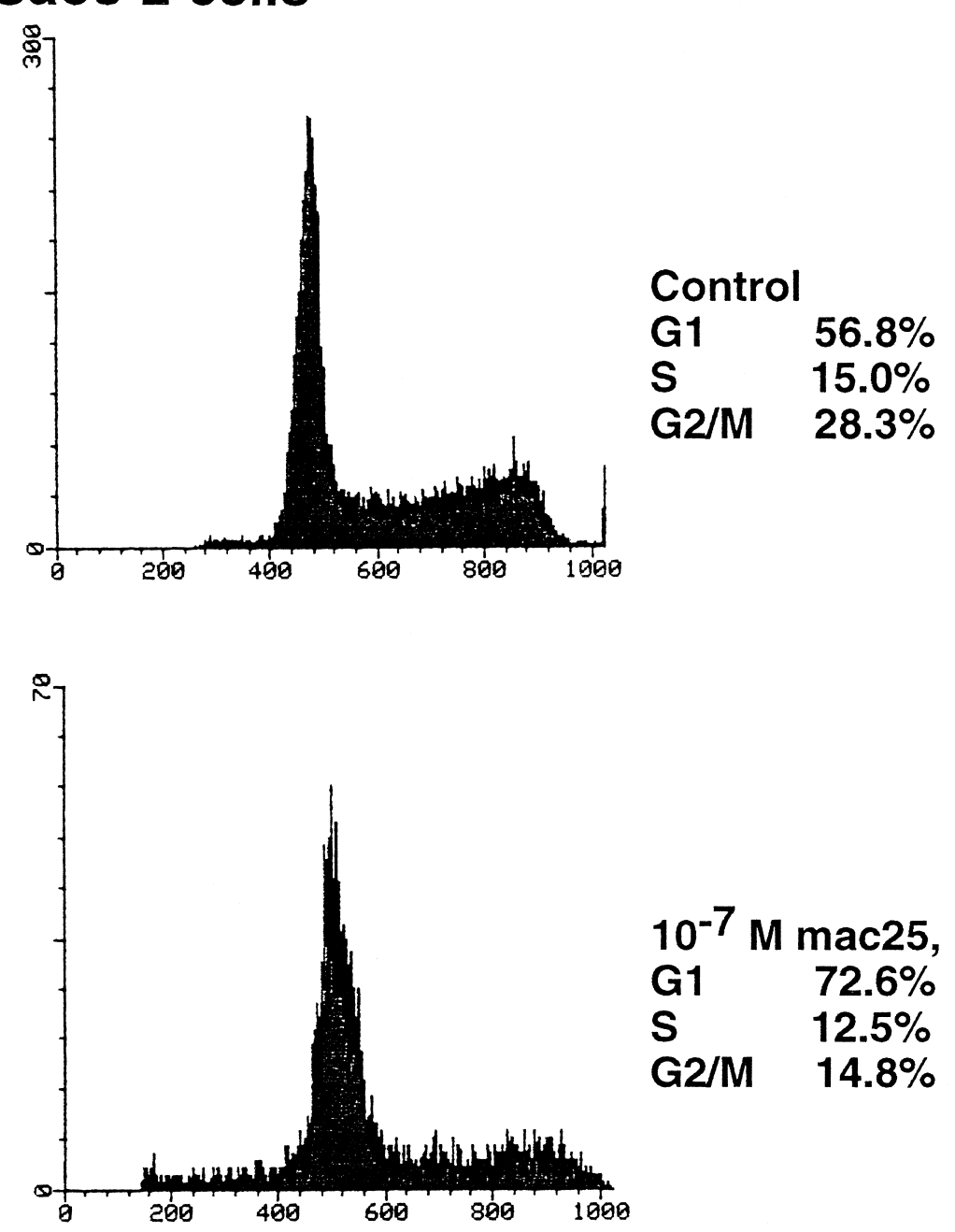

\section{$10^{-7} \mathrm{M}$ mac25, $12 \mathrm{hr}$}

G1 $\quad 72.6 \%$

S $12.5 \%$

G2/M $\quad 14.8 \%$

Fig. 6. Cell-cycle analysis of mac25-treated and untreated Saos-2 cells. The upper panel shows the results of FACS analysis of untreated Saos-2 cells. The lower panel shows the results after treatment with mac25 for 12 hr. Fractions of cells in the G1, S and G2/M phases are indicated on the right.

may be associated with initiation of these cancers.

mac25 associates directly with IGFs and it has been proposed that mac 25 is a member of the family of IGF-BPs (9). IGF signaling must also be important for the regulation of cell growth. In fact, p53 up-regulates the expression of IGF-BP3 in association with growth inhibition (30). Homology to FGFR was also found in c-terminal region (Fig. 1). The multifunctional character of mac25 protein (in TGF$\beta$, IGF and FGF signaling) may reflect its roles in the growth suppression, cell death and cellular senescence.

\section{Acknowledgments}

This work was supported in part by The Ryoichi Naito Foundation for Medical Research and by a Cancer Research Grant from the Sagawa Cancer Research Foundation, Japan. Recombinant human activin A, Lot\# $15365-36(1)$, was provided by the $\mathrm{Na}$ tional Hormone and Pituitary Program, the National Institute of Diabetes and Digestive and Kidney Diseases, the National Institute of Child Health and Human Development, and the U.S. Department of Agriculture, U.S.A. 

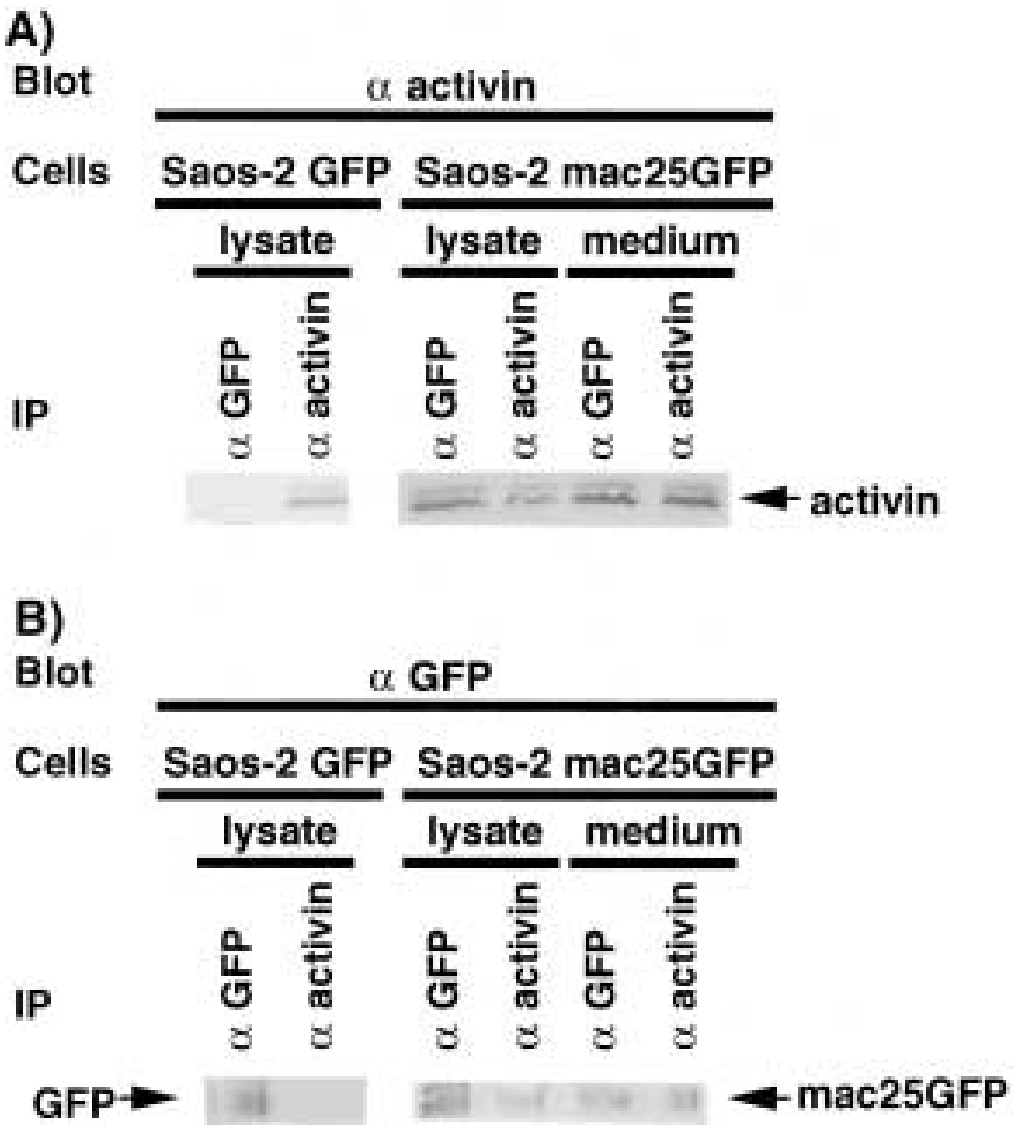

Fig. 7. Binding of mac25 and activin A. (A) Proteins in lysates and media after immunoprecipitation with antibody against GFP $(\alpha G F P)$ or activin A ( $\alpha$ activin). Saos-2 cells were transfected with the control vector (Saos-2 GFP) or the mac25-GFP fusion construct (Saos-2 mac25GFP) and proteins were probed with antibody against activin A. Activin A was detected after precipitation with antibody against GFP in all samples except those derived from the lysate of Saos-2 GFP. (B) The same lysates and media were probed with antibody against GFP. The mac25-GFP fusion protein was detected in all samples of Saos-2 mac25GFP. The GFP protein was detected in lysate of Saos-2 GFP after precipitation with antibody against GFP, but it was not detected in lysate of Saos-2 GFP after precipitation with antibody against activin $\mathrm{A}$.

\section{References}

1. Murphy M, Pykett MJ, Harnish P, Zang KD, George DL. (1993) Cell Growth Differ. 4: 715-722.

2. Swisshelm K, Ryan K, Tsuchiya K, Sager R. (1995) Proc. Natl. Acad. Sci. U.S.A. 92: 4472-4476.

3. Ning Y, Weber JL, Killary AM, Ledbetter DH, Smith JR, Pereira-Smith OM. (1991) Proc. Natl. Acad. Sci. U.S.A. 88: 5635-5639.

4. Kato MV, Sato H, Tsukada T, Ikawa Y, Aizawa S, Nagayoshi M. (1996) Oncogene 12: 1361-1364.

5. Patthy L, Nikolics K. (1993) Trends Neurosci. 16: 7681.

6. Rupp F, Payan DG, Magill-Solc C, Cowan DM, Scheller RH. (1991) Neuron 6: 811-823.

7. Shimasaki S, Koga M, Esch F, Cooksey K, Mercado M, Koba A, Ueno N, Ying SY, Ling N, Guillemin R. (1988) Proc. Natl. Acad. Sci. U.S.A. 85: 4218-4222.

8. Sugino K, Kurosawa N, Nakamura T, Takio K, Shimasaki S, Ling N, Titani K, Sugino H. (1993) J. Biol. Chem. 268: 15579-15587.

9. Oh Y, Nagalla SR, Yamanaka Y, Kim HS, Wilson E, Rosenfeld RG. (1996) J. Biol. Chem. 271: 30322-30325.

10. McCutchan JH, Pagano JS. (1968) J. Natl. Cancer Inst. 41: 351-357.
11. Akaogi K, Okabe Y, Sato J, Nagashima Y, Yasumitsu H, Sugahara K, Miyazaki K. (1996) Proc. Natl. Acad. Sci. U.S.A. 93: 8384-8389.

12. Glozak MA, Rogers MB. (1996) Dev. Biol. 179: 458-470.

13. Okazawa H, Shimizu J, Kamei M, Imafuku I, Hamada H, Kanazawa I. (1996) J. Cell Biol. 132: 955-968.

14. Nakamura T, Takio K, Eto Y, Shibai H, Titani K, Sugino H. (1990) Science 247: 836-838.

15. El-Dairy WS, Tokino T, Veculescu VE, Levy DB, Parsons R, Trent JM, Lin D, Mercer WE, Kinzler KW, Vogelstein B. (1993) Cell 75: 817-825.

16. Hannon GJ, Beach D. (1994) Nature 371: 257261.

17. Toyoshima H, Hunter T. (1994) Cell 78: 67-74.

18. Buetow KH, Murray JC, Israel JL, London WT, Smith M, Kew M, Blanquet V, et al. (1989) Proc. Natl. Acad. Sci. U.S.A. 86: 8852-8856.

19. Zhang WD, Hirohashi S, Tsuda H, Shimosato Y, Yokota J, Terada M, Sugimura T. (1990) Jpn. J. Cancer Res. 81: 108-111.

20. Yeh SH, Chen PJ, Lai MY, Chen DS. (1996) Gastroenterology 110: 184-192.

21. Rosin MP, Cairns P, Epstein JI, Schoenberg MP, Sidransky D. (1995) Cancer Res. 55: 5213-5216. 
22. Mitra AB, Murty VV, Li RG, Pratap M, Luthra UK, Chaganti RS. (1994) Cancer Res. 54: 4481-4487.

23. Mullokandov MR, Kholodilov NG, Atkin NB, Burk RD, Johnson AB, Klinger HP. (1996) Cancer Res. 56: 197-205.

24. Sato S, Nakamura Y, Tsuchiya E. (1994) Cancer Res. 54: 5652-5655.

25. Petersen I, Langreck H, Wolf G, Schwendel A, Psille R, Vogt P, Reichel MB, Ried T, Dietel M. (1997) Br. J. Cancer 75: 79-86.

26. Hammoud ZT, Kaleem Z, Cooper JD, Sundaresan RS, Patterson GA, Goodfellow PJ. (1996) Cancer Res. 56: 4499-4502.
27. Califano JA, Johns MM, Westra WH, Lango MN, Eisele D, Saji M, Zeiger MA, et al. (1996) Int. J. Cancer 69: 442-444.

28. Pershouse MA, El-Naggar AK, Hurr K, Lin H, Yung WK, Steck PA (1997) Oncogene 14: 369-373.

29. Takeuchi S, Bartram CR, Wada M, Reiter A, Hatta Y, Seriu T, Lee E, Miller CW, Miyoshi I, Koeffler HP. (1995) Cancer Res. 55: 53775382.

30. Buckbinder L, Talbott R, Velasco-Miguel S, Takenaka I, Faha B, Seizinger BR, Kley N. (1995) Nature 377: 646-649. 